НАУКОВИЙ ВІСНИК

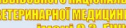

S-ientifice messenger of Liviv National University of

1

(5)

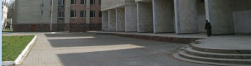

СЕРЯя: ВЕТТРИНАРНН НАУКИ

Том 22 № 100

2020
Науковий вісник Дьвівського національного університету ветеринарної медицини та біотехнологій імені С.3. Гжицького. Серія: Ветеринарні науки

\section{Scientific Messenger of Lviv National University of Veterinary Medicine and Biotechnologies. Series: Veterinary sciences}

UDC 619:616.995.121.56

\title{
Monitoring of cattle echinococcosis on the results of post slaughter expertise of carcases
}

\section{S. I. Rustamova}

Azerbaijan Scientific Research Veterinary Institute, Baku, Azerbaijan Republic

Article info

Received 16.10.2020 Received in revised form 17.11.2020

Accepted 18.11.2020

Azerbaijan Scientific Research Veterinary Institute,

Kondelen Str., 8 P.O. Box: AZ1000, Baku, Azerbaijan Republic Tel.: +38-050-330-21-90 E-mail:bav13@meta.ua
Rustamova, S. I. (2020). Monitoring of cattle echinococcosis on the results of post slaughter expertise of carcases. Scientific Messenger of Lviv National University of Veterinary Medicine and Biotechnologies. Series: Veterinary sciences, 22(100), 116-122. doi: 10.32718/nvlvet10020

Echinococcus granulosus is widespread among cattle, sheep and goats in seasonal pastures. Moreover, this invasion is considered one of the most dangerous zoonoses. The purpose of this work was to compare the indicators of the extensiveness and intensity of invasion of different-aged slaughter livestock (fattening bulls of 1.5-2 years old and 4-7 years old cows) from the herds of four regions of Azerbaijan located in different zones of the country. Based on the results of the expertise of 100 carcasses from each region, it was concluded that the indicators of the extensiveness of the invasion of echinococcosis in cattle were similar and ranged from 21.0-25.0\% with the invasion intensity of 9.36-11.96 specimens of cysts/carcass. To identify larvocysts of Echinococcus granulosus, the carcasses and internal organs of cattle (lungs, liver, kidneys, spleen, heart) were examined. In this case, the extensiveness (EI) and intensity (II) of echinococcosis invasion were established. The indicator of the latter was the number of larvocysts detected in the examined organs of the invaded cattle. Their localization and accounting were determined by counting the echinococcal larvocysts separately in three positions: liver, lungs and others (abdominal cavity, kidneys, spleen and heart). In many cases (73.6\%) the larvocysts were simultaneously found in the liver and lungs. There is a tendency towards an increase in the incidence rate of cattle with age. So, the extensiveness of the invasion of cows was 2.5 times higher than that of the young, and the intensity of invasion was 2.3 times higher. In the future, it is planned to establish the extensiveness and intensity of echinococcosis invasion among flocks of sheep arriving from summer distant mountain pastures in comparison with the number of flocks staying year-round in local near-village pastures.

Key words: Echinococcus granulosus, expertise, cattle, extent and intensity of invasion.

\section{Мониторинг эхинококкоза крупного рогатого скота по результатам после- убойной экспертизы туш}

\author{
С. И. Рустамова
}

Азербайджанский научно-исследовательский ветеринарный институт, г. Баку, Азербайджанская Республика

Echinococcus granulosus имеет широкое распространение среди крупного рогатого скота, овеи и коз, находящихся на сезонныхх пастбищах. При этом, данную инвазию относят к числу наиболее опасных зоонозов. Целью данной работы было сопоставление показателей экстенсивности и интенсивности инвазии разновозрастного убойного поголовья скота (откормочное быки 1,5-2-х годичного возраста и 4-7-летние коровы) от стад из четырех районов Азербайджана, находящихся в разных зонах страны. Для выявления ларвочыст Echinococcus granulosus, осмотру подвергали туши и внутренние органы крупного рогатого скота (легкие, печень, почки, селезенку, сердие). При этом устанавливали экстенсивность (ЭИ) и интенсивность (ИИ) эхинококкозной инвазии. Показателем последней было число ларвоцыст выявленных в исследуемых органах инвазированного скота. Локализацию и учет их, определяли путем подсчета эхинококковых ларвоцыст отдельно по трех позициях: печень, легкие и иные (брюшная полость, почки, селезенка и сердие). По результатам экспертизы 100 туш от каждого района, сделано заключение, что показатели экстенсивности инвазии эхинококкоза у крупного рогатого скота были близко подобными и колебались в пределах 21,0-25,0\% при интенсивности инвазии 9,36-11,96 экз. иист/туша. В значительном большинстве наблюдениях (73,6\%) ларвоцысты одновременно находи- 
ли в печени и легких. Прослеживается тенденция нарастания показателей заболеваемости скота с возрастом. Так ЭИ коров была выле от молодняка в 2,5, а ИИ - в 2,3 разы. В дальнейшем планируется планируется установить экстенсивность и интенсивность эхинококкозной инвазии среди отар овец прибывших с летних отгонных горных пастбиш в сопоставлении с поголовьем отар находящихся круглогодично на местных присельских пастбищах.

Ключевые слова: Echinococcus granulosus, экспертиза, крупный рогатый скот, экстенсивность и интенсивность инвазии.

\section{Введение}

Известно, что окончательными хозяевами эхинококка являются: собака (основной хозяин), волк, реже шакал, лисица, а промежуточными - различные травоядные и всеядные копытные животные, в том числе все виды продуктивных животных и человек (Craig et al., 2015; Loos et al., 2018; Heidari et al., 2019).

У обитающих в тонкой кишке основного хозяина взрослых особей от стробил отторгаются и выделяются наружу зрелые членики, заполненные яйцами. Отторжение члеников происходит приблизительно два раза в месяц (La-Rocca et al., 2019; Xin et al., 2019).

В пищевом тракте промежуточного хозяина из проглоченных онкосфер высвобождаются шестикрючные личинки, которые проникают в кровеносные сосуды кишечной стенки и током крови заносятся в печень. Большая часть их там и оседает. В связи с этим ларвоцисты эхинококка встречаются в печени чаще, чем в других органах.

Высокий уровень данной инвазии наблюдается повсеместно, особенно в зонах развитого пастбищного животноводства. Анализ научных публикаций за последние несколько десятилетий, свидетельствует о широком распространении эхинококкоза среди скота во всех административных образованиях Кавказского региона.

В условиях Дагестана эхинококкоз крупного рогатого скота распространен повсеместно. Пораженность животных эхинококкозом составляет 20,9 \% при интенсивности инвазии 66,7 цист в среднем. В отдельных хозяйствах зараженность крупного рогатого скота достигала $42,8 \%$. Из обнаруженных цист Echinococcus granulosus фертильными оказались $41,2 \%$ и ацефало-цистами - 58,8 \%. Чаще поражены были легкие (55\%), печень (43\%), до 2 \% поражены сердце, селезенка, почки и другие органы (Makhieva et al., 2010).

Позже этот же коллектив авторов опубликовал новые наблюдения. По которых в Республике Дагестан зараженность крупного рогатого скота эхинококками во всех 5-ти районах составила 37,3 \%. Однако степень инвазирования скота в разрезе районов очень варьировала и составила: в Казбековском - 45,6 \%; в Буйнакском - 42,5\%; в Сергаколинском - 29,1\%; в Кайтагском - 25,4 \%; в Каякентском - 22,5 \%.

В Чеченской Республике у крупного рогатого скота были обнаружены эхинококки: в Гудермесском районе - у 32,1 \% в Веденском - у 28,7 \%; Шалинском - у 19,1\% обследованного поголовья (Makhieva et al., 2012).

Другие исследователи в предгорной зоне Дагестана среди поголовья крупного скота возбудителя Echinococcus granulosus выделяли среди 17,5 \% обследованных животных. При этом местом нахожде- ния их чаще $(66,6 \%)$ являлась печень, реже (30\%) легкие, и незначительно (3,4 \%) - иные органы (Ataev et al., 2017).

В Республики Дагестан эхинококкоз встречается: в популяциях взрослого зебувидного местного крупного рогатого скота с ЭИ - 28,3\%; у буйволов - $21,0 \%$, при ИИ, соответственно, 3-42; 5-28 экз./особь. Но из 16 крупных населенных пунктов равнинной, предгорной и горной зоны, эхинококкоз лошадей регистрировался только в 3-х районах с колебаниями ЭИ от 4,6 до $6,7 \%$, при обнаружении всегда ацефалоцист E. granulosus. Причинами распространения эхинококкоза у молодняка скота в сельской месности являются: использование территории поселений в качестве скотопрогонных маршрутов; высокая ЭИ эхинококкоза собак; круглогодовое пастбищное содержание скота (Eldarova, 2017).

В Кабардино-Балкарской Республике эхинококкоз животных и человека приобрел экспансивный характер с образованием региональных эпидемиологических и эпизоотологических значимых природных, сельских и городских очагов инвазии. Экстенсивность инвазии эхинококкоза собак в регионе определяется в среднем 66,9 \%. В равнинной зоне эхинококкоз дворовых собак встречается с ЭИ - 64,9\%, в предгорной зоне $-66,1$, в горной зоне - 70,7. Главной причиной распространения инвазии является отсутствие плановой дегельминтизации собак, санитарного просвещения персонала и населения.

Эхинококкоз крупного рогатого скота регистрировался во всех районах республики с ЭИ, в среднем $21,7 \%$ при ИИ 16,98 $\pm 1,37$ экз./особь. Экстенсивность инвазии эхинококкоза буйволов составила $16,7 \%$ при интенсивности инвазии, в среднем $10,42 \pm 1,28$ экз./особь. Экстенсивность инвазии составила у яков 14,7 \%, при интенсивности инвазии в среднем 19,3 $\pm 2,1$ экз./особь (Elkarova, 2010).

Сопоставляя показатели зараженности скота разного возраста на эхинококкоз в зависимости от технологии содержания в условиях Кабардино-Балкарской Республики авторы установили, что животные одного возраста при разной технологии содержания инвазировались с разными показателями экстенсивности и интенсивности инвазии. Так, при стойловопастбищной технологии было инвазовано 20,0% поголовья, при отгонно-пастбищном содержании 60,0 \%. При стойловом содержании крупный рогатый скот был свободен от Echinococcus granulosus (Mamaeva et al., 2011).

Впоследствие иной коллектив авторов показал, что в Кабардино-Балкарской Республике все районы являются неблагополучными по эхинококкозу крупного рогатого скота. По данным гельминтологических вскрытий печени, легких и других паренхиматозных органов скота, возбудитель Echinococcus granulosus 
установлен во всех предгорных приусадебных хозяйствах. Экстенсивность инвазии колебалась у взрослого крупного рогатого скота (коровы) от 25,7 до $36,4 \%$. В среднем экстенсивность инвазии составила $31,5 \%$ при средней интенсивности инвазии $16,4 \pm 1,5$ экз. цист/гол (Tokhaeva et al., 2014).

В регионе Центрального Кавказа (Ингушетия) установлено, что в эпизоотологии заболевания животных эхинококкозом ведущую роль играют домашние животные. Зараженность крупного рогатого скота составляла $28,4 \%$, а с возрастом ЭИ увеличивалось до $30,9 \%$. При этом чаще поражены были легкие $56,2 \%$, реже печень - 33,4 \%. ИИ в среднем составила 9,1 цист. Зараженность собак эхинококками составляла $70 \%$. Этим же автором выявлено, что во внешней среде яйца эхинококков способны выживать в течение года и более. Сильная обсемененность почвы наблюдали: в кошарах (от 47,4 до 100 \%) и скотопрогонных трассах (15,8-28,6\%). Обсемененность зелени на огородах вблизи кошар достигала 60 \% (Plieva, 2007).

Республика Северная Осетия-Алания является одной из наиболее неблагополучных по эхинококкозу территорий Северного Кавказа. При этом эхинококкоз зарегистрирован во всех административных районах, со средней инвазированностью КРС 11,89 \% с максимальной инвазированностью в предгорной - 14,55 \% и минимальной в лесостепной зонах $-7,5$ \%. Ларвальные эхинококки обнаружены в различных органах КРС (печень, легкие, селезенка, сердце), с частотой: $79,81 \% ; 68,23 \% ; 6,05 \%$ и 5,51\%, соответственно. Степень инвазированности эхинококком коррелировала с возрастом, чем старше - тем больше цист. В печени коров, старше 10 лет, ИИ достигала 33-37 цист, в легких 38-40; в печени и легких - более 60 , тогда как у молодых животных (до 3-х лет) обнаруживали единичные цисты. А основную роль в распространении эхинококкоза на территории республики выполняют “пастушеские” собаки (Bagaeva, 2009).

Другие авторы из этой же республики отмечали, что у крупного рогатого скота среди заболеваний паразитарной этиологии эхинококкоз занимает первое место. При этом результаты проведенных ими бактериологических исследований свидетельствовали, что 50 \% проб из внутренних органов, пораженных ларвальным эхинококкозом, были обсеменены бактериями группы кишечной палочки, а из 35 \% проб были выделены бактерии рода Salmonella (Dyachenko et al., 2014).

На территории Северо-Западного региона Кавказа гидатидный эхинококкоз занимает от 33,13 до 46,79 \% в структуре всех паразитарных заболеваний. При эхинококкозной инвазии у скота происходят изменения в качественном и количественном составе органов и тканей: снижается суммарное количество связанных аминокислот; многократно увеличивается суммарное количество свободных аминокислот; увеличивается количество альдегидов и возрастает концентрация сложных эфиров. При длительном скармливании таких продуктов зарегистрировано их негативное действие на организм лабораторных животных (Petrik, 2012).
При стойлово-пастбищном содержании телят инвазированность эхинококкозом их начинали диагностировать в 7-12-месячном возрасте, при ЭИ - $20 \%$, а ИИ-эхинококков - 10 экз./гол. У молодых коров (второй-третьей лактации) показатель ИИ $=40 \%$, а ИИ 31 экз./гол. В приусадебных хозяйствах предгорной зоны Северного Кавказа зараженность эхинококками крупного рогатого скота колеблется в пределах 25,7$36,4 \%$ при интенсивности инвазии до 23,0 экз. цист/гол. (Tokhaeva et al., 2014).

Относительно распространения эхинококкоза скота в Юго-Западном регионе Кавказа за последние два десятилетия в доступной литературе публикаций мы не находили.

О состоянии рассматриваемой инвазии на территории Азербайджана во второй половине прошлого столетия и двадцать лет нынешнего - наличные тематичные сообщения довольно редкие. Так, характеристику распространения и эпизоотологические особенности эхинококкоза животных подавали периодически местные ученные (Asadov \& Mamikov, 1965; Gurbanov, 1981; Sadakhov, 1986; Alibekov, 2000).

По сообщению М. Алиева, в Азербайджане зараженность эхинококками косули в предгорной зоне выявлялась до $35,0 \%$, дикого кабана - 68,5 \%, серны - 42,5 \% при ИИ соответственно 2-11; 4-23 и 2-15 экз./особь. В горных районах зараженность закавказской популяции туров ларвоцыстами E. granulosus составила 9,2\% при интенсивности инвазии 17 экз./гол. Причем все ларвоцысты в их печени и легких были фертильными при обнаружении 1,816,7 тыс. протосколексов в 1 мл эхинококковой жидкости. В полупустынной зоне эхинококкозом заражены сайгаки с ЭИ - 20,6 \% при обнаружении 3-26 экз. ларвоцыст, которые в 100 \% случаях были представлены фертильными цистами. Аборигенный крупный рогатый скот зимой заражен эхинококкозом с ЭИ $34,8 \%$, овцы - 50,6 \% при ИИ соответственно 5-42 и 3-38 экз./особь (Aliev, 1997).

Одновременно данный паразит выявляли у животных в одном, двух, трех и четырех органах, в разных вариациях, в 32,6 \% случаях были поражены сразу печень и легкие; (у людей - в двух: печень и легкие, соответственно $89,55 \%$ и 10,45 \%). В последние годы отмечается распространение этого заболевания не только среди сельского, но и городского населения, причем в большинстве случаев - среди лиц молодого и зрелого возрастов, что еще раз подчеркивает социальную значимость этой проблемы (Agaeva, 2020).

\section{Материалы и методы}

Опыты проводили осенью 2020 года на троих пунктах убоя (ПУ) г. Баку и одном убойном пункте г. Сумгаит. В дни наблюдений крупный рогатый скот (откормочные быки преимущественно 1,52-годичного возраста и разновозрастные выбракованные коровы 4-7 лет) поступали для убоя на каждый убойный пункт с 4-х районов страны, расположенных в разных её зонах с расстояниями между ними 200500 км, а именно: 
№ 1 - ООО “ЭСЭ” - Имишлинский,

№ 2 - "Терекиме" - Агджабединский,

№ 3 - "Уджал Эргюн" - Апшеронский,

№ 4 - Сумгаит - Шамкирский.

За рабочий день забивали от 20 до 40 голов скота. На каждом пункте осматривали по 100 туш, при этом ветеринарно-санитарную экспертизу продуктов убоя животных проводили в соответствии с наличными “Методическими указаниями” (Nemakova, 2016).

Для выявления ларвоцыст Echinococcus granulosus осмотру подвергали туши и внутренние органы крупного рогатого скота (легкие, печень, почки, селезенку, сердце). При этом устанавливали экстенсивность (ЭИ) и интенсивность (ИИ) эхинококкозной инвазии. Показателем последней было число ларвоцыст выявленных в исследуемых органах инвазированного скота. Локализацию и учет их определяли путем подсчета эхинококковых ларвоцыст отдельно по трех позициях: печень, легкие и иные (брюшная полость, почки, селезенка и сердце).

\section{Результаты и обсуждение}

Из показателей таблицы 1 следует, что общая зараженность откормочных бычков эхинококками со всех 4 районов была невысокой и составила: ЭИ 13,85 \%, при ИИ - 5,81 цыст/туша. При этом наиболее высокую ЭИ $(16,98 \%$, при ИИ - 4,89) отмечали от поголовья с Шамкирского района, а наименьшую $(11,11 \%$ при ИИ - 6,14) - от поголовья с Имишлинского района. Размеры ларвоцыст были диаметром от 0 до 8-12 см. С их общего количества (186 экз.) - локализовались: в печени 126 экз. (67,7\%); в легких 58 экз. $(31,2)$ и 2 экз. $(0,1 \%)$ - в иных органах.

Таблица 1

Мониторинг эхинококкоза при послеубойной ветеринарно-санитарной экспертизе туш бычков

\begin{tabular}{cccccc}
\hline \multirow{2}{*}{ № } & \multicolumn{5}{c}{ Показатели } \\
\cline { 2 - 6 } ПУ & Осмотрено, туш & $\begin{array}{c}\text { Выявлено } \\
\text { ларвоцыст, туш }\end{array}$ & ЭИ, \% & $\begin{array}{c}\text { Кол-во ларвоцыст, } \\
\text { всего, экз. }\end{array}$ & $\begin{array}{c}\text { ИИ, экз./1 тушу } \\
(\min -\text { max })\end{array}$ \\
\hline № 1 & 63 & 7 & 11,11 & 43 & $6,14(2-11)$ \\
№ 2 & 44 & 6 & 13,64 & 42 & $7,0(1-12)$ \\
№ 3 & 71 & 10 & 14,08 & 57 & $5,7(1-10)$ \\
№ 4 & 53 & 9 & 16,98 & 44 & $4,89(1-11)$ \\
Всего & 231 & 32 & 13,85 & 186 & $5,81(4,9-7,0)$ \\
\hline
\end{tabular}

Общая зараженность коров эхинококками со всех 4-х районов (табл. 2) была более высокой и составила: ЭИ - 34,91 \%, при ИИ - 13,25 цыст/туша. При этом наиболее высокую ЭИ $(41,38$ \%, при ИИ - 12,42) отмечали от поголовья с Апшеронского района, а наименьшую $(30,36$ \% при ИИ - 13,06) - от поголовья с Агджабединского района. Сопоставляя показатели инвазированности коров относительно аналогичных критериев убойного молодняка, с возрастом скота прослеживается общая тенденция роста ЭИ в 2,5 раза, а ИИ - в 2,3 раза.

Размеры ларвоцыст были диаметром от 1 до 10-15 см. (рис.1-4). На одном органе находились цисты разных размеров, что указывало на многократное инвазирования коров в разные годы.
С общего количества ларвоцыст (818 экз.) - локализовались: в печени 477 экз. (58,3 \%); в легких 327 экз. (40,0 \%) и 14 экз. (1,7\%) - в иных органах.

Обобщенные возрастные данные убойного поголовья (табл. 3) показывают, что совместная инвазированность его составила: ЭИ - 22,75 \%, при ИИ 11,03 цыст/туша. При этом наиболее высокую ЭИ $(25,0 \%$, при ИИ - 11,96) отмечали от поголовья с Шамкирского района, а наименьшую ЭИ (21,0% при ИИ - 11,19) - от поголовья с Имишлинского района. С их общего количества (818 экз.) - локализовались: в печени 477 экз. (58,3\%); в легких 327 экз. (40,0\%) и 14 экз. (1,7 \%) - в иных органах. Во всех наблюдениях преобладало количество туш, в которых ларвоцысты одновременно находили в печени и легких $(73,6 \%)$.

\section{Таблица 2}

Мониторинг эхинококкоза при послеубойной ветеринарно-санитарной экспертизе туш коров

\begin{tabular}{|c|c|c|c|c|c|}
\hline \multirow[b]{2}{*}{$\begin{array}{l}\text { № } \\
\text { ПУ }\end{array}$} & \multicolumn{5}{|c|}{ Показатели } \\
\hline & $\begin{array}{l}\text { Осмотре-но, } \\
\text { туш }\end{array}$ & $\begin{array}{c}\text { Выявлено } \\
\text { ларвоцыст,туш }\end{array}$ & ЭИ, \% & $\begin{array}{c}\text { Кол-во ларвоцыст, } \\
\text { всего, эКз. }\end{array}$ & $\begin{array}{l}\text { ИИ, экз./1 тушу } \\
\text { (min-max) }\end{array}$ \\
\hline № 1 & 37 & 14 & 37,84 & 192 & $11,57(5-23)$ \\
\hline № 2 & 56 & 17 & 30,36 & 222 & $13,06(3-21)$ \\
\hline № 3 & 29 & 12 & 41,38 & 149 & $12,42(4-22)$ \\
\hline № 4 & 47 & 16 & 34,04 & 255 & $15,94(6-31)$ \\
\hline Всего & 169 & 59 & 34,91 & 818 & $13,25(11,6-15,9)$ \\
\hline
\end{tabular}




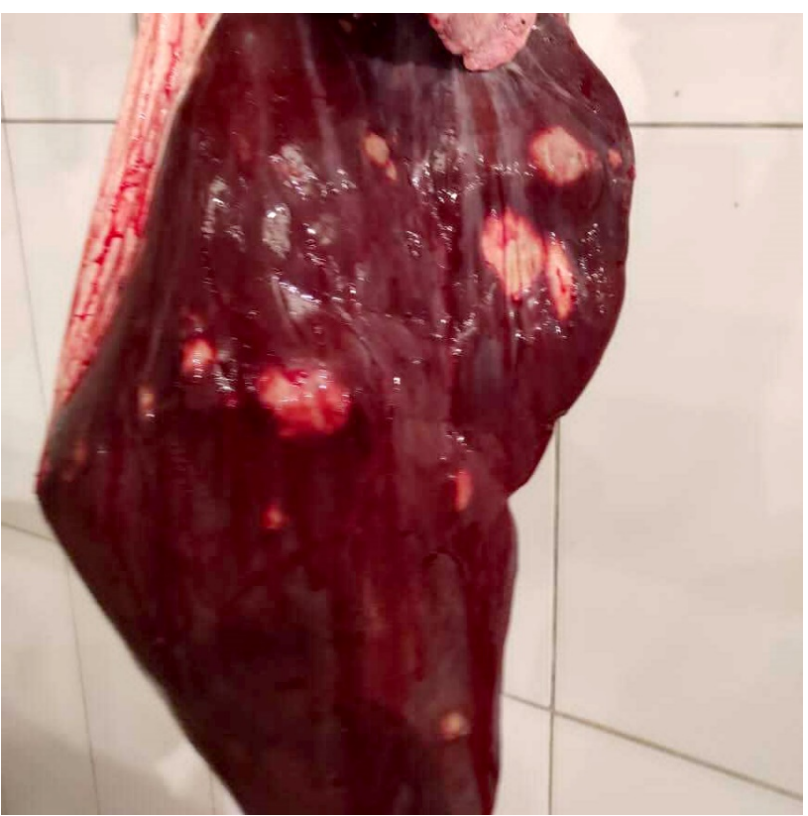

Рис. 1. Ларвоцысты на печени быка

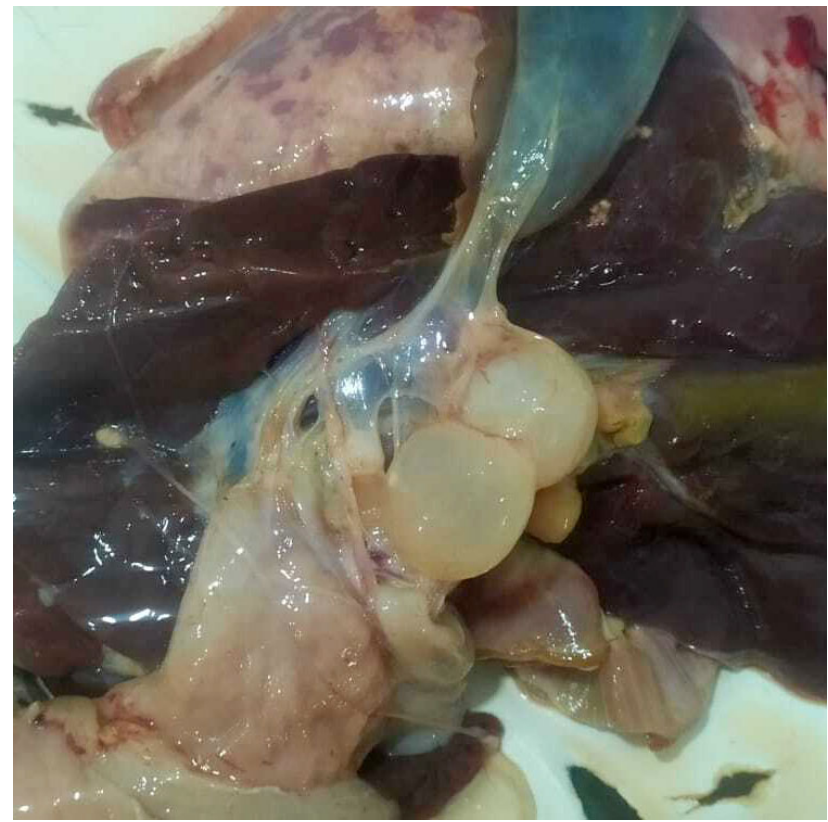

Рис. 2. Ларвоцысты на печени коровы

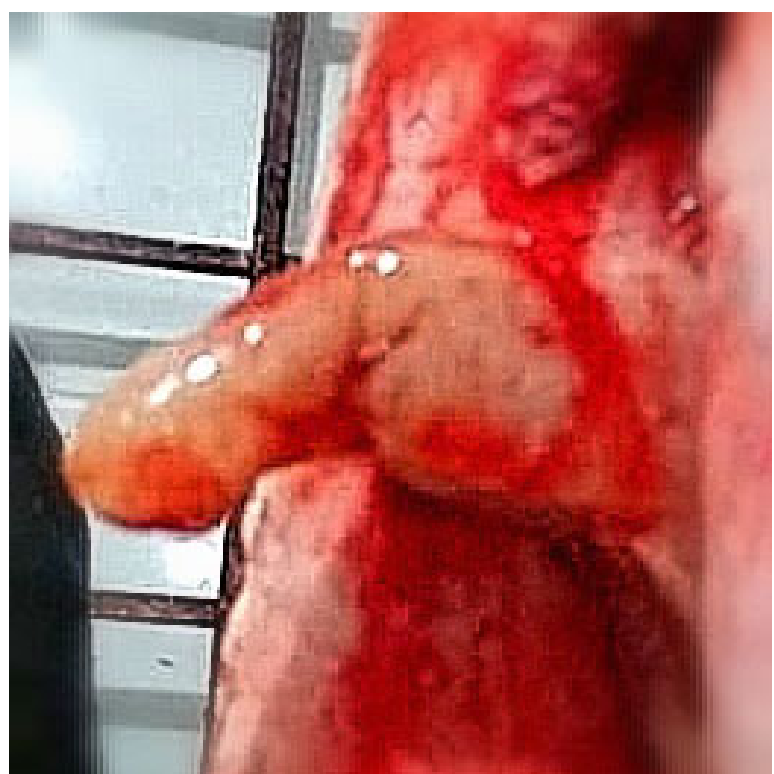

Рис. 3. Ларвоцыста на легких быка

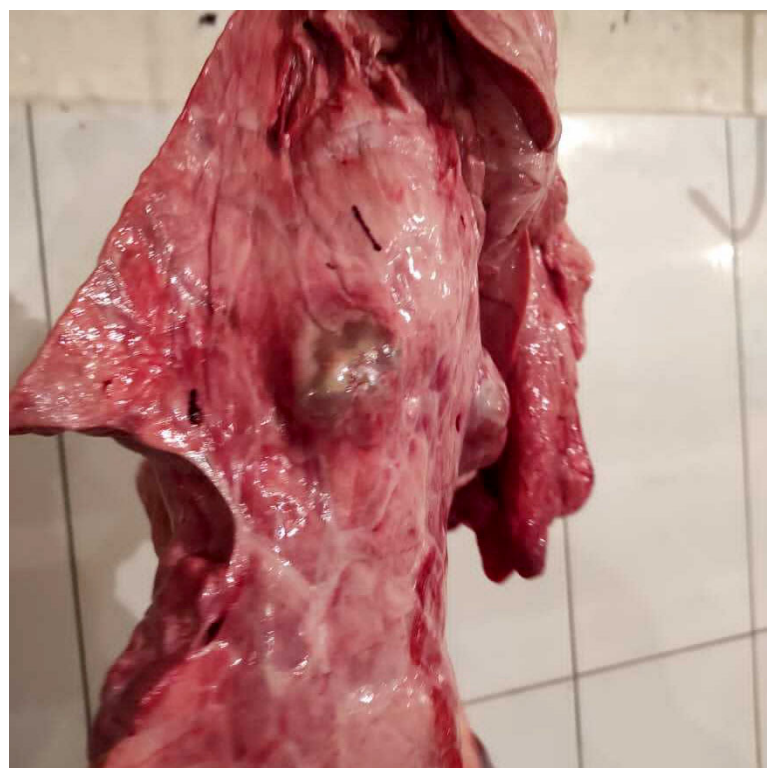

Рис. 4. Ларвоцысты на легких коровы

\section{Таблицы 3}

Мониторинг эхинококкоза при послеубойной ветеринарно-санитарной экспертизе туш крупного рогатого скота в целом по районам

\begin{tabular}{cccccc}
\hline \multirow{2}{*}{ № } & \multicolumn{5}{c}{ Показатели } \\
\cline { 2 - 6 } ПУ & $\begin{array}{c}\text { Осмотрено, } \\
\text { туш }\end{array}$ & $\begin{array}{c}\text { Выявлено } \\
\text { ларвоцыст,туш }\end{array}$ & ЭИ, \% & Кол-во ларвоцыст, всего, & $\begin{array}{c}\text { ИИ, } \\
\text { экз. }\end{array}$ \\
\hline № 1 & 100 & 21 & 21,0 & 235 & 11,19 \\
№ 2 & 100 & 23 & 23,0 & 264 & 11,48 \\
№ 3 & 100 & 22 & 22,0 & 206 & 9,36 \\
№ 4 & 100 & 25 & 25,0 & 299 & 11,96 \\
Всего & 400 & 91 & 22,75 & 1004 & 11,03 \\
\hline
\end{tabular}

\section{Заключение}

Таким образом, в разных районах Азербайджана показатели экстенсивности инвазии эхинококкоза у крупного рогатого скота колебались в пределах 21,0 25,0 \% при интенсивности инвазии 9,36-11,96 экз. цист/туша. 
В значительном большинстве наблюдениях (73,6 \%) ларвоцысты одновременно находили в печени и легких.

Прослеживается тенденция нарастания показателей заболеваемости скота с возрастом. Так, ЭИ коров была выше молодняка в 2,5, а ИИ - в 2,3 раза.

Перспектива дальнейших исследований. Планируется установить экстенсивность и интенсивность эхинококкозной инвазии среди отар овец, прибывших с летних отгонных горных пастбищ, в сопоставлении с поголовьем отар, находящихся круглогодично на местных присельских пастбищах.

\section{References}

Agaeva, A. N. (2020). Distribution of the causative agent of echinococcosis of sheep (Echinococcus granulosus) in the territories of the Absheron Peninsula and Khyzyn district of the Republic of Azerbaijan. Agricultural science. 1, 43-45. doi: 10.32634/0869-81552020-334-1-43-45 (in Azerbaijan).

Alibekov, S. K. (2000). Epizootological features of saiga echinococcosis in the semi-desert zone of Azerbaijan. Veterinary of Azerbaijan, 3, 18-20 (in Azerbaijan).

Aliev, M. A. (1997). Infection of cattle, buffaloes and zebu and sheep E. granulosus in Azerbaijan. Tr. Me. FIELDS, 60, 21-25 (in Azerbaijan).

Asadov, S. M., \& Mamikov, Yu. F. (1965). On the characteristics of the spread of hydatid echinococcosis in domestic ruminants and pigs in Azerbaijan. Proceedings of the Institute of Zoology of the Academy of Sciences of Az. SSR,. T. XXIV, 43-46 (in Azerbaijan).

Ataev, A. M., Zubairova, M. M., Karsakov, N. T., \& Gazimagomedov, M. T. (2017). Echinococcosis of domestic animals in Dagestan. Mate. report international scientific conf. "Theory and practice of control of parasitic diseases". M., 18, 30-32 (in Russian).

Bagaeva, U. V. (2009). Epizootology and epidemiology of larval echinococcosis in the Central Caucasus region: Abstract. dis. ... k-ta biol. Science. M. (in Russian).

Craig, P., Mastin, A., van Kesteren, F., \& Boufana, B. (2015). Echinococcus granulosus: Epidemiology and state-of-the-art of diagnostics in animals. Vet Parasitol, 213(3-4), 132-148. doi: 10.1016/j.vetpar.2015.07.028.

Dyachenko, Yu. V., Maslennikova, A. S., Mikhailenko, V. V., Lutsuk, S. N., \& Tolokonnikov, V. P. (2014). Invasion of Echinjcoccus granulosus ruminants in the Republic of North Ossetia-Alania and some sanitarymicrobiological and pathomorphological characteristics of their internal organs. Modern problems of science and education, 6.; URL: https://www.scienceeducation.ru/ru/article/view?id=16237 (in Russian)

Eldarova, L. H. (2017). Features of bioecology and epizootology of canine teniidosis and echinococcosis of farm animals in Dagestan: Abstract. dis. ... k-ta biol. Science. M. (in Russian).

Elkarova, Z. Z. (2010). Epizootological and epidemiological characteristics of foci of echinococcosis of animals and humans in the ecosystem of the Kabardino-
Balkarian Republic: Abstract. dis. ... k-ta biol. Science. M. (in Russian).

Gurbanov, F. Sh. (1981). Survival of teniid dog eggs in lowland and highland pastures of Azerbaijan. Bull. All-Russian. in-that helminthologists, 29, 56-57 (in Russian).

Heidari, Z., Sharbatkhori, M., Mobedi, I., Mirhendi, S. H., Nikmanesh, B., Sharifdini, M., Mohebali, M., Zarei, Z., Arzamani, K., \& Kia, E. B. (2019). Echinococcus multilocularis and Echinococcus granulosus in canines in North-Khorasan Province, northeastern Iran, identified using morphology and genetic characterization of mitochondrial DNA. Parasit Vectors, 12(1), 606. doi: 10.1186/s13071-019-3859-z.

La-Rocca, S., Farias, J., Chalar, C., Kun, A. E., \& Fernandez, V. (2019). Echinococcus granulosus: Insights into the protoscolex F-actin cytoskeleton. Acta Trop, 199, 105122. doi: 10.1016/j.actatropica.2019.105122.

Loos, J. A., Nicolao, M. C., \& Cumino, A. C. (2018). Metformin promotes autophagy in Echinococcus granulosus larval stage. Mol Biochem Parasitol, 224, 61-70. doi: 10.1016/j.molbiopara.2018.07.003.

Makhieva, B. M., Shamkhalov, M. V., Musaev, Z. G., \& Shamkhalov, V. M. (2010). Prevalence of echinococcosis in cattle in Dagestan. Russian Journal of Parasitology, 1, 52-55 (in Russian).

Makhieva, B. V., Shamkhalov, M. V., Shamkhalov, V. M., Magomedshapiev, G. M., \& Maksudova, A. S. (2012). Distribution and age dynamics of echinococcosis and tenuicol cystocercosis of cattle in the foothills of Dagestan and the Chechen Republic. Russian Journal of Parasitology, 3, 56-61 (in Russian).

Maksud oglu. A. R. (2003). Echinococcosis of a liver with defeat of bilious ways (diagnostics, surgical treatment): Dis. ... Dr. Med. Nauk. M. (in Russian).

Mamaeva, S. S., Bittirova, M. I., Yusupova, Z. H., \& Shikhalieva, M. A. (2011). Echinococcosis and dicroceliosis of cattle with grazing and grazing in the North Caucasus. Russian Journal of Parasitology, 4, 77-79 (in Russian).

Nemakova, N. P. (2016). Veterinary and sanitary examination of products of slaughter of animals at parasitic diseases: Methodical instructions. Krasnoyarsk (in Russian).

Petrik, O. B. (2012). Evaluation of the quality and safety of slaughter products in hydatid echinococcosis of farm animals: on the example of the North-Western region of the Caucasus: Abstract. dis. ... k-ta biol. Science. M. (in Russian).

Plieva, A. M. (2007). Ecological and epizootological features of echinococcosis of animals in the Central Caucasus region: Abstract. dis. ... Dr. Biol. Science. M. (in Russian)

Sadakhov, I. A. (1986). Epizootological and epidemic features of echinococcosis of animals in the Azerbaijan SSR. Sb.: Abstracts dokl. IX Congress of the AllUnion Society of Helminthologists. M., 139-140 (in Russian).

Tokhaeva, A. I., Kishchikova, F. I., Birdzhiev, B. M., Shipshev, B. M., Harbiev, I. H., Bersanukaeva, R. B., Shahbiev, H. H., Mantaeva, S. S., \& Bittirov, A. M. 
(2014). On the epizootological situation of echinococcosis of cattle in the foothills of the North Caucasus. Russian Journal of Parasitology, 1, 76-78 (in Russian).
Xin, Q., Yuan, M., Li, H., Lu, J., Song, X., \& Jing, T. (2019). In vitro efficacy of ampelopsin against Echinococcus granulosus and Echinococcus multilocularis. J Vet Med Sci, 81(12), 1853-1858. doi: 10.1292/jvms.19-0347. 